\title{
Gender Stereotypes Underlie Child Custody Decisions
}

\author{
Ana Beatriz Dillon Esteves \\ London School of Economics \\ UNITED KINGDOM
}

\section{Roxana Kreimer}

Universidad Nacional de La Plata ARGENTINA

\author{
Luiza Lopes Franco Costa \\ Universidade do Estado do Rio de Janeiro \\ BRAZIL
}

\author{
Noel Struchiner \\ Ivar R. Hannikainen \\ Pontificia Universidad Católica de Río de Janeiro \\ BRAZIL
}

\begin{abstract}
Using hypothetical divorce cases we examine the role of gender stereotypes in decisions about child custody. Good mothers received greater custody allocations than did good fathers across a tightly-matched pair of vignettes in three culturally-distinct samples: Argentina, Brazil and the United States (Study 1). Two follow-up studies indicated that the warmth dimension of stereotype content partly accounted for the asymmetry in custody awards: The proportion of maternal-primary custody was predicted by the tendency to ascribe warmth-related traits-such as friendliness, generosity or trustworthiness - to mothers (Study 2) and associate them to female over male nouns (Study 3). We also found that endorsing shared custody mitigated the asymmetry in custody awards documented in our studies. Together, these results highlight the interplay of stereotyped attitudes and egalitarian commitments in the context of judicial decisions about child custody.
\end{abstract}

In the $20^{\text {th }}$ century, the belief in women's "natural superiority" with regard to childrearing frequently served as a legal argument for the award of sole custody to mothers. As traditional gender roles were called into question, parenting laws in socially progressive states were subsequently revised and gender-neutral custody laws prioritizing "the child's best interests" are now the norm (Parkinson, 2015). But have such gender-neutral laws given rise to more egalitarian custody allocations in practice?

Some evidence suggests not, at least not immediately. In Brazil, for instance, custody was granted to mothers in $86.3 \%$ of divorce cases involving minor children in 2013 (IBGE, 2014), and similar percentages have been observed in the United States
(Braver, Ellman, Votruba, \& Fabricius, 2011; Cancian \& Meyer, 1998). Numerous factors may contribute to this disproportion: First, mothers may have handled a majority of care-taking functions prior to divorce. In line with this, a recent survey finds that women still exercise greater household and childcare duties than men even in dualearner households (LeanIn \& McKinsey, 2015). Second, nationally representative studies show higher rates of domestic violence (e.g., Tjaden \& Thoennes, 2000) and substance abuse (van Etten, Neumark, \& Anthony, 2001) by men than by women. Finally, the above percentage aggregates litigious and non-litigious custody decisions, and fathers may voluntarily forfeit parenting rights more frequently than do mothers. These considerations probably 
account for much of the aforementioned disproportion in child custody outcomes.

In this study, we consider an additional factor which may have eluded the attention of legal scholars (but see Fabricius, Braver, Schenck, \& Diaz 2010; Warshak, 1996). Namely, could latent gender stereotypes in the judge's mind shape custody awards, even under gender-neutral custody laws? A wealth of past research reveals gender stereotypes and their real-world consequences, which we review below in order to contextualize our present research question.

The stereotype content model (Fiske, Cuddy, \& Glick, 2007; Fiske, Cuddy, Glick, \& Xu, 2002) argues that stereotypes about social groups can be arranged on a two-dimensional plane. A first dimension, warmth, refers to immediate assessments about whether we generally 'like' someone or their social group. Characteristics like trustworthiness, friendliness, kindness, and benign intentions make up the warmth dimension. A second dimension, competence, encapsulates whether we generally 'respect' the person or social group, and commonly depends on the attribution of virtues like intelligence, success, and organization. Warmth and competence are independent dimensions of social perception, such that individuals and groups may be perceived as both competent and warm, as warm but incompetent, and so on.

Stereotype content may help to characterize the nature of sexist prejudice. On one hand, competence traits seem to be more readily attributed to men (see Abele, 2003). For instance, a United Kingdom survey showed that parents estimated significantly higher IQs for their sons than for their daughters (Furnham, Reeves, \& Budhani, 2002). This stereotype is equally present in professional environments: In a recent study, science faculty from research universities rated one of two applications for a laboratory manager position, which differed only in the candidate's name
("Jennifer" vs. "John"). The male candidate was rated significantly more competent and hirable, and was offered a higher starting salary than the female candidate, even though their CVs were identical (MossRacusin, Dovidio, Brescoll, Graham, \& Handelsman, 2012).

In contrast, warmth traits appear to be more strongly associated to women: People exhibit more favorable attitudes towards women than towards men (Nosek \& Banaji, 2001), and a closer look at the content of these positive evaluations reveals that women are perceived as more helpful, gentle, supportive, kind, understanding, and/or committed than men (Eagly, Mladinic, \& Otto, 1991; Rudman \& Kilianski, 2000).

How these stereotypes are linked to existing sex differences, i.e., whether they reflect (Jussim, 2012) or cause (Jost \& Kay, 2005) them, is matter of heated debatestoked in part by meta-analytic (Flore \& Wicherts, 2015) and field (Stricker \& Ward, 2004) evidence that effects of stereotype threat may have been overstated. In either case, the association of benevolent characteristics to women-in particular, to women who occupy mother, wife and caretaker roles-may constitute a subtle, and relatively overlooked, form of sexism (see ambivalent sexism in Glick \& Fiske, 1996 1997).

A number of studies document how apparently benevolent attitudes reinforce traditional gender roles: First, a study in nine nations revealed that the endorsement of benevolent sexism (e.g., "A good woman ought to be set on a pedestal by her man") predicts sex-typed mate preferences in both men and women: i.e., in men, the desire for a younger mate who is a "good cook and housekeeper"; in women, the desire for an older mate who should have "good financial prospects" (Lee, Fiske, Glick, \& Chen, 2010; see also Montañés, et al., 2012). Furthermore, lab studies have shown that benevolent, but not hostile, forms of 
sexism undermine women's performance on mock job applications (Dardenne, Dumont \& Bollier, 2007), professional ambitions (Rudman \& Heppen, 2003), and support for gender equality movements (Becker \& Wright, 2011) — consistent with evidence that benevolent stereotypes reinforce a patriarchal status quo just as much as unabashed forms of oppression, but are not as strongly resisted by victims of gender inequality.

Collectively, these studies demonstrate the existence of gender stereotypes that associate competence more easily to men and warmth more easily to women, with each reifying existing gender roles and occupational differentiation. Some stereotypes have been shown to reflect real trait differences between groups (Jussim et al., 1996) and sex differences in empathy constitute a reliable example (ChristovMorre et al., 2014; Richell et al., 2003). Yet, even when stereotypes are accurate, it is widely agreed that one should not infer an individual's traits from stereotypes of the group(s) to which they belong. This threat looms large in the judiciary-whose objective is to protect citizens from discrimination and not to serve as its vehicle.

At the outset, we presented national statistics indicating that, despite shifts toward shared custody legislation, judges still tend to allocate custodial rights primarily to mothers. We then reviewed evidence that gender stereotypes are ubiquitous, and exert various influences on preferences, judgment and interpersonal behavior. Together, these past findings motivate the hypothesis that forms the basis for the present report: In three complementary experiments, we examine whether gender stereotypes contribute to the prevalence of maternal-primary custody in judicial systems with gender-neutral parenting law. To gauge the generalizability of stereotype effects upon custody decisions, we conduct our primary study (Study 1) in three different languages and cultures, drawing on both law students and lay respondents.

\section{Study 1}

In Study 1, we probe both explicit and implicit preferences regarding child custody. To assess explicit beliefs, we ask participants whether in general "all rights and responsibilities concerning the children should be shared equally by both parents in case of divorce". Participants also report their endorsement of hostile and benevolent sexism, employing the Ambivalent Sexist Inventory (Glick \& Fiske, 1997). Since benevolent sexism involves stereotyped beliefs about women which may bring to bear on child-rearing (e.g., "Women, compared to men, tend to have a superior moral sensibility"), individuals who hold such attitudes may be more likely to explicitly favor maternal primary custody.

However, preferences may also adopt an implicit form - as documented, for instance, in the study of racial prejudice (Dovidio \& Gaertner, 2000; Pearson, Dovidio \& Gaertner, 2009). Consider for instance, an overtly progressive (egalitarian) judge evaluating a custody dispute. The judge may award maternal-primary custody and justify the decision on the basis of independent criteria, such as, greater emotional stability, work obligations, and so on. And yet, through experimental comparison, we can ask: What would the outcome have been had their qualifications been reversed? Specifically, would the judge have awarded paternal-primary custody in that case? In Study 1, we employ this experimental paradigm in a mixed-factorial design, to evaluate whether implicit preferences arise in the context of custody awards.

\section{Methods}

All data and materials are available on the Open Science Framework at: https://osf.io/utycm/. 


\section{Power analysis}

In order to estimate the required sample size for Study 1, we conducted a pilot study $(\mathrm{N}=40)$ based on the two custody cases (as described in Table 1). We observed a medium effect of the parent gender manipulation, Cohen's $d=0.53, \eta^{2}=.07$. A power analysis with conventional error rates $(\alpha=.05,1-\beta=.80)$ recommended a sample size of 114 .

\section{Participants}

We drew separate samples from three different countries: Argentina, Brazil and the United States. Details about the composition of each sample are provided below:

Argentina. One hundred and thirty-one volunteers $\left(69 \%\right.$ women, age $e_{\text {mean }}=44.4$ years) were recruited through word of mouth and online networks.

Brazil. Eighty law students (49\% women, age $_{\text {mean }}=24.6$ years) at a private university in Minas Gerais, Brazil, volunteered to participate in a short study after class. One participant did not complete our primary dependent measures and was therefore excluded from all analyses.

United States. One hundred and twentynine participants $(43 \%$ women, age mean $=$ 35.8 years), recruited from Amazon's online labor marketplace (www.mturk.com), took part in exchange for a small payment.

Thus, our samples varied in terms of age, gender distribution, cultural background and legal background, enabling us to understand whether our primary hypothesis holds across different populations.

\section{Procedure}

After providing informed consent, participants viewed two cases describing a married couple in the midst of divorce, battling over child custody in court. In order to motivate unequal custody assignments, vignettes were written so that one parent was somewhat warmer than the other parent (i.e., kinder towards the children, more unselfish, and so on).
Case 1 read as follows:

Katie and Matt have two children, Alice and Gabe, who are 8 and 10 years old respectively. Both parents have stable jobs: Matt is a nutritionist, while Katie is a history professor. They contribute equally to household and child-related expenses. Their dynamic in the daily care of the children was always wellestablished. Katie prepared breakfast and lunch for the kids, and took them to school before heading to work. Matt would pick the kids up from school after work, make them dinner and take them to swimming lessons.

After several years being married, the couple decided to divorce for a few reasons: they weren't supporting each other as much anymore, and they were in disagreement about basic aspects of their children's education. Both parents are contesting custody over their children in court. They were, however, determined to do so in such a way to cause the least harm to Alice and Gabe.

Katie is known among family friends to be more affectionate and caring with the kids. She loves to tell them bedtime stories, and readily shows them affection through hugs and kisses. Matt, in contrast, has a colder personality. He doesn't normally show affection, and doesn't deal well with the children's emotional needs. He prefers to handle matter-of-fact and routine issues, like overseeing the children's homework and meals.

Katie, in turn, sometimes travels on weekends to conferences and talks, and misses out on important events with the kids, such as ballet shows and piano recitals.

Case 2 involved a bus driver and a cashier, in which the bus driver had been selfish and dishonest with home finance and the cashier was more caring towards the children (see Supplementary Materials).

In order to determine whether participants exhibit an implicit preference, we compared custody awards in Cases 1 and 2 to awards in identical versions with parents' names transposed (so the fathers were warmer than the mothers). However, presenting both versions of the same case (e.g., Better-Father and Better-Mother versions of Case 1) in sequence would introduce demand characteristics by rendering our experimental comparison 
transparent to participants. So, we paired levels of better parent with a different case on each trial: In other words, participants did not see the same case twice, but saw one case with a better father and one case with a better mother.

In a balanced, incomplete block design, better parent gender (Better Mother; Better Father), and case (Nutritionist \& Professor; Driver \& Cashier) were entered as withinsubject factors. Cases were also presented in a counterbalanced order, and case order and better-parent order were randomized across participants.

Custody was assigned for each case on a 7-point Likert scale from -3: "Sole custody to [worse parent]", to 0: "Shared custody", to 3: "Sole custody to [better parent]". Our primary hypothesis concerns the main effect of better parent gender, controlling for case and the case $\times$ better-parent interaction: specifically, that custody awards will be greater in the Better Mother (versus the Better Father) condition.
Next, participants completed the Ambivalent Sexism Inventory (Glick \& Fiske, 1997), yielding individual difference measures of both hostile and benevolent sexism, and reported their views on shared custody (see Supplementary Materials). Lastly, participants optionally provided basic demographic information: age, gender, and political orientation.

\section{Results}

For each sample, summary statistics of custody allocations on both cases are reported in Table 1 below. Shared custody was the most popular decision, resulting in leptokurtic distributions. So, we conducted Wilcoxon rank sum tests to assess the influence of our better-parent inversion. All three samples revealed significant differences on both cases (see Figure 1). Common language effect sizes (CL; McGraw \& Wong, 1992) suggested that the probability of assigning greater custody in the Better Mother condition than in the Better Father condition ranged between $57 \%$ and $64 \%$.

Table 1: Summary statistics (n, mean and standard deviation) for each national sample, by case and the betterparent manipulation. We also report the results of each Wilcoxon rank-sum test ( $\mathrm{Z}$ test statistic, $\mathrm{p}$ value, and common language effect size).

\begin{tabular}{|c|c|c|c|c|c|c|c|c|}
\hline \multirow[b]{2}{*}{ Sample } & \multirow[b]{2}{*}{ Case } & \multicolumn{2}{|r|}{ Mom } & \multirow{2}{*}{\multicolumn{2}{|c|}{$\begin{array}{l}\text { Dad } \\
\qquad \text { M (SD) }\end{array}$}} & \multicolumn{3}{|c|}{ Rank sum test } \\
\hline & & $\mathrm{N}$ & $\mathrm{M}(\mathrm{SD})$ & & & Z & $p$ & CL \\
\hline \multirow[t]{2}{*}{ ARGENTINA } & $\begin{array}{l}\text { Nutritionist \& } \\
\text { Professor }\end{array}$ & 62 & $0.180 .46)$ & 68 & $-0.01(0.78)$ & 2.06 & .039 & .57 \\
\hline & Driver \& Cashier & 68 & $0.42(0.98)$ & 62 & $-0.08(0.49)$ & 3.39 & .001 & .64 \\
\hline \multirow[t]{2}{*}{ BRAZIL } & $\begin{array}{l}\text { Nutritionist \& } \\
\text { Professor }\end{array}$ & 40 & $0.48(1.04)$ & 39 & $-0.03(0.63)$ & 2.58 & .010 & .64 \\
\hline & Driver \& Cashier & 39 & $0.69(0.92)$ & 40 & $0.13(1.07)$ & 2.29 & .022 & .64 \\
\hline \multirow[t]{2}{*}{$\begin{array}{l}\text { UNITED } \\
\text { STATES }\end{array}$} & $\begin{array}{l}\text { Nutritionist \& } \\
\text { Professor }\end{array}$ & 53 & $0.75(1.09)$ & 63 & $0.17(1.13)$ & 2.46 & .014 & .62 \\
\hline & Driver \& Cashier & 63 & $0.52(1.11)$ & 59 & $-0.08(1.24)$ & 2.73 & .006 & .62 \\
\hline (pooled) & & 339 & $0.50(1.00)$ & 339 & $0.00(0.96)$ & 6.18 & .000 & .62 \\
\hline
\end{tabular}




\section{Father $\square$ Mother}

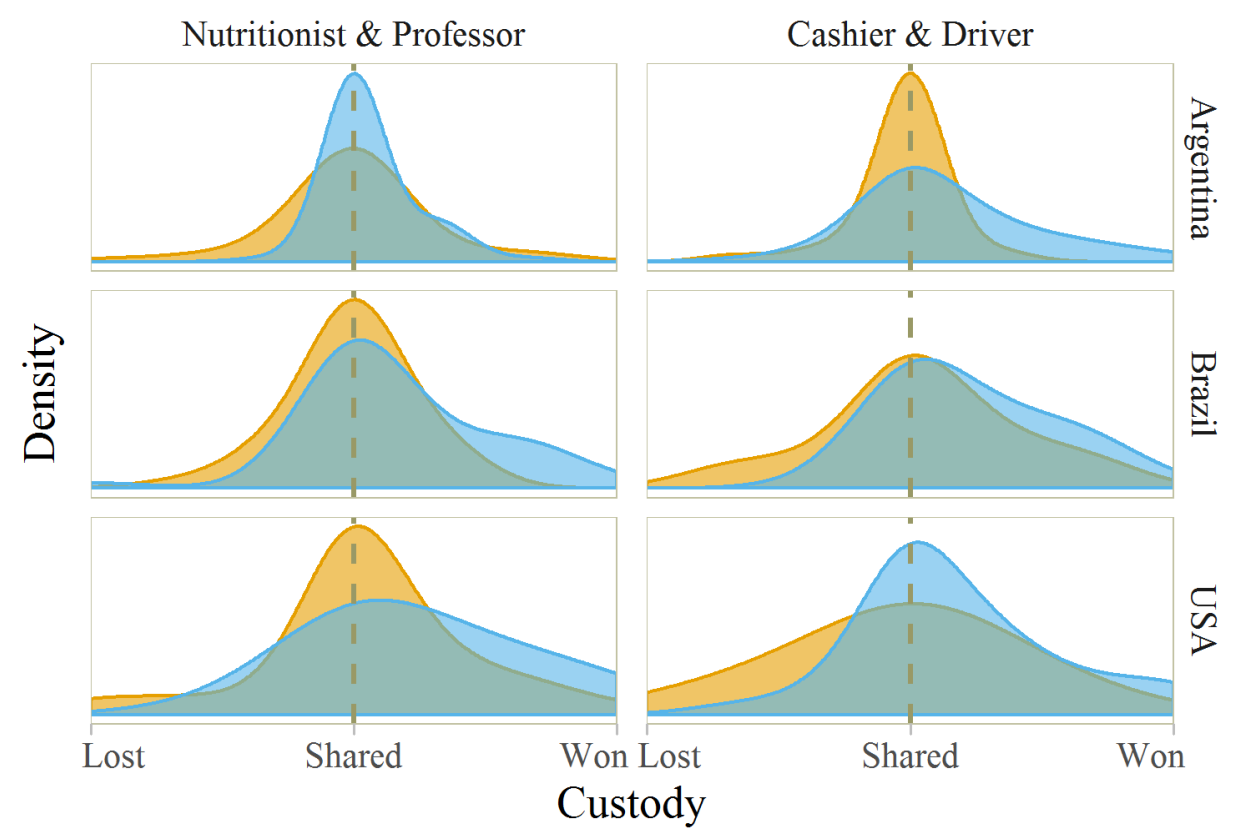

Figure 1. Density curve of custody awards by better parent, with cases as horizontal facet and country as vertical facet.

To provide a general estimate of the effect, we also conducted a mixed-effects model, with subject nested within sample as random effects, allowing a random intercept by participant, and random slopes of scenario and parent gender at the sample level. The effect of the parent gender manipulation remained significant, $B=0.42$ $[0.32,0.80], t=3.23, p=.001$. In contrast, there was no main effect of case or interaction with parent gender, $p \mathrm{~s}>.250$.

\section{Ambivalent Sexism Inventory.}

Excluding participants who left any blanks, we averaged hostile and benevolent sexism items in order to generate separate indices (HS: $\alpha=.80$; BS: $\alpha=.83$ ) for our participants.

Consistent with past research (Glick \& Fiske, 1996), endorsement of hostile sexism positively tended to correlate with a conservative political orientation and was greater among males than among females (see Table 1). Both conservatism, $\mathrm{B}=0.25$, $\mathrm{t}=6.99$, and gender, $\mathrm{B}=0.36, \mathrm{t}=3.50$, independently predicted hostile sexism, $p$ s < .001 (but age did not, $p>.250$ ).
Some corresponding relationships with benevolent sexism were observed for political orientation, but not gender. Together, these results echo past perspectives suggesting that benevolent sexism is not as strongly rejected by women as is hostile sexism (Glick \& Fiske, 1997). In a mixed-effects model, political orientation predicted benevolent sexism, B $=0.19, t=6.10, \mathrm{p}<.001$, such that conservative/right-leaning participants tended to have higher scores on the benevolent sexism subscale than did liberal/left-leaning participants. Age and gender did not predict benevolent sexism in this model, $p \mathrm{~s}>.250$.

Does the asymmetry in custody allocations depend on benevolent sexist beliefs?

We employed a mixed-effects model to examine whether benevolent sexism moderated the effect of the gender manipulation on custody decisions, entering condition (1: better mom; 0 : better dad), case $(1 ; 2)$, BS and HS $z$-scores and the interaction of each predictor with condition. The main effect of the parent-gender 
manipulation remained significant, $B=$ $0.41, t=3.37, p<.001$. In contrast, there were no main effects or interactions of either subscale on the ASI, $p$ s $>.250$, suggesting that the observed asymmetry in custody allocations did not depend on the endorsement of benevolent sexist views.

Table 2: Correlation table (Pearson's $r, p$-value, $n$ ): Ambivalent Sexism Inventory and demographics.

(1)

AR $\quad$ BR $\quad$ US AR $\quad$ BR
(2)

(3)
(4)

\begin{tabular}{lllllllllllll}
\hline AR & BR & US & AR & BR & US & AR & BR & US & AR & BR & US \\
\hline
\end{tabular}

1 HS

\begin{tabular}{|c|c|c|c|c|c|c|c|c|c|c|c|c|c|}
\hline \multirow{3}{*}{2} & & .504 & .295 & .682 & - & \multirow{3}{*}{-} & \multirow[b]{3}{*}{ - } & & & & & & \\
\hline & BS & .000 & .016 & .000 & & & & & & & & & \\
\hline & & 120 & 66 & 125 & & & & & & & & & \\
\hline \multirow{3}{*}{3} & & .043 & .297 & -.152 & .115 & .055 & -.066 & - & \multirow{3}{*}{ - } & & & & \\
\hline & Age & .645 & .015 & .090 & .210 & .657 & .465 & & & & & & \\
\hline & & 120 & 67 & 125 & 120 & 68 & 125 & & & - & & & \\
\hline \multirow{3}{*}{4} & \multirow{3}{*}{ Gen. } & $\begin{array}{l}- \\
.190\end{array}$ & $\begin{array}{l}- \\
.288\end{array}$ & -.142 & .061 & -.068 & -.093 & .229 & -.205 & -.029 & - & \multirow{3}{*}{ - } & \\
\hline & & .038 & .017 & .114 & .507 & .577 & .301 & .012 & .079 & .753 & & & \\
\hline & & 120 & 68 & 125 & 120 & 69 & 125 & 120 & 74 & 125 & & & - \\
\hline \multirow{3}{*}{5} & \multirow{3}{*}{ Pol. } & .339 & .240 & .467 & .261 & -.015 & .479 & -.147 & -.050 & -.025 & -.089 & -.118 & .025 \\
\hline & & .000 & .050 & .000 & .004 & .903 & .000 & .110 & .684 & .784 & .332 & .328 & .786 \\
\hline & & 120 & 67 & 125 & 120 & 67 & 125 & 120 & 70 & 125 & 120 & 71 & 125 \\
\hline
\end{tabular}

Note: HS: Hostile sexism. BS: Benevolent sexism. Gen.: Gender (coded as 1: female and 0: male). Pol.: Politics (coded as 1: very liberal/left; 7: very conservative/right). AR: Argentina. BR: Brazil. US: United States. Statistically significant correlations are highlighted using bold font.

Abstract support for shared custody.

At the end of the study, we asked participants whether they agree with shared custody in the abstract via a single statement "In case of divorce, all rights and responsibilities concerning the children should be shared equally by both parents," using a 6-point scale. ${ }^{1}$ In line with past

\footnotetext{
${ }^{1}$ In Brazil, participants were also asked whether they would approve or reject Brazil's current law on
}

research (Braver et al., 2011; Fabricius et al., 2010), most participants agreed with the principle of shared custody $(97.2 \%, n=$ 72/74; $M=5.57, S D=.81$ ).

Does endorsement of shared custody reduce the maternal preference?

shared custody on a 4-point scale. Most participants $(90.9 \% ; n=70 / 77)$ approved the current formulation of shared custody in Brazil's civil code with "some" or "no" modifications. 
Next, we examined whether our single item of support for shared custody moderates the observed asymmetry in custody awards in a mixed-effects model. As with benevolent sexism, we entered condition (1: better mom; 0 : better dad), together with case and support for shared custody (centered) and their two-way interactions with condition as predictors. The main effect of the parent-gender manipulation remained highly significant, $B$ $=0.57, t=3.68, p<.001$. Meanwhile, the effect of abstract support for shared custody on custody awards varied by condition: Specifically, support for shared custody tended to negatively predict custody decisions in the better mother condition, $B$ $=-0.25[-0.47,-0.04], t=-2.30, p=.021$, but not in the better father condition, $B=0.06$ $[-0.11,0.23], t=0.66, p=.51$.

\section{Discussion}

Public opinion (Braver et al., 2011) and legal scholarship (Stamps, 2002; Warshak, 1996) have attributed a maternal preference to family court. To our knowledge no past studies have sought to provide evidence for this claim in an experimental setting. By simply transposing the names of parents across tightly-matched pairs of cases, we found an asymmetry in custody allocations in three different national samples: Namely, good mothers received greater custody allocations than did good fathers.

We tested two potential moderators of maternal preference. First, we predicted that the attribution of subjectively benevolent traits to women, such as purity and sweetness, would moderate the asymmetry in custody allocations. This prediction, however, was not supported. Second, the emergence of a maternal preference in our sample co-existed with overwhelming support for the doctrine of shared child custody in the abstract. A vast majority of participants approved shared custody legislation, and agreed with the principle of shared custody. Furthermore, endorsement of shared custody appeared to mitigate the effect of the better-parent manipulation.

These results suggest that the preference for maternal-primary child custody is present across cultures, but that egalitarian principles regarding childcare duties appear to reduce its effect on custody allocations.

\section{Study 2}

Study 1 revealed that the manipulation of parents' gender influenced custody allocations in different cultures. We hypothesized that this effect might stem from differences in the parents' perceived warmth and/or competence. In Study 2, we ask participants to rate parents on attributes related to warmth and competence, and investigate whether warmth attributions mediate the effect of better parent gender on custody decisions.

\section{Methods}

\section{Power analysis}

In Study 1, we observed a medium effect of the parent gender manipulation, Cohen's $d=0.51$. We reasoned, then, that any mediator of this effect would exert an effect on custody awards no smaller than the effect of the independent variable, i.e., greater than or equal to $d=0.51$. Based on this estimate of the effect of warmth on custody awards $\left(f=.255\right.$, or $\left.\eta_{\mathrm{p}}^{2}=.061\right)$, a power analysis with conventional error rates $(\alpha=.05,1-\beta=.80)$ recommended a sample size of 123 participants.

\section{Participants}

We recruited a hundred and forty-seven participants $\left(44 \%\right.$ women, age $e_{\text {mean }}=36.5$ years) from Amazon's online labor marketplace (www.mturk.com), who completed a 3-minute study in exchange for monetary compensation.

\section{Procedure}

In a 2 (case: Nutritionist \& Professor; Driver \& Cashier) $\times 2$ (better parent: Mother; Father) between-subjects design, participants were randomly assigned to 
view one of the custody cases employed in Study 1.

Before determining custody, participants were asked to assess the parents' "character and personality" through 5 warmth (loving, kind, caring, friendly, trustworthy) and 5 competence (smart, successful, responsible, organized, talented) traits. For each trait, participants reported whether each adjective better describes: -5 "[worse parent's name] much better", 0: "both equally", or 5: "[better parent's name] much better". On the following page, participants were asked to award custody on a 7-point scale as in Study 1.

We held three predictions in Study 2 . We predicted that (1) custody awards and (2) warmth attributions would be greater in the Mother versus Father condition. Third, if our first two predictions are borne out, we also predict that (3) warmth attributions will mediate the effect of better-parent on custody awards.

\section{Results}

Replicating Study 1, a two-way ANOVA revealed a main effect of the better parent manipulation, $\mathrm{F}(1,143)=12.36, p<.001$, $\eta_{\mathrm{p}}^{2}=.086$, but no effect of scenario, $\mathrm{F}(1$, $143)=0.04, p=.84$, or scenario $\times$ betterparent interaction, $\mathrm{F}(1,143)=0.03, p=.86$. Wilcoxon rank sum tests revealed that the effect of the parent gender manipulation was significant for the Driver \& Cashier case, $z=2.49, p=.013, \mathrm{CL}=.66$, but not the Nutritionist \& Professor case, $z=1.64, p$ $=.100, \mathrm{CL}=.61$-although Study 2 was not adequately powered to detect the effect separately for each case.

In line with Study 1, most participants endorsed shared custody in the abstract (M $=5.24, \mathrm{SD}=1.02$ ), as confirmed also in a signed-rank test against the scale midpoint, $z=10.11, p<.001$. Furthermore, an ANCOVA indicated that endorsement of shared custody moderated the asymmetry in custody awards, $\mathrm{F}(1,139)=6.22, p=$ .014. That is, endorsement of shared custody significantly reduced custody awards in the better mother condition (as in Study 1), $B=-0.71$ [-1.32, -0.09], $t=-2.26$, $p=.025$, and also marginally increased them in the better father condition, $B=0.37$ $[-0.05,0.80], t=1.73, p=.085$.

\section{Warmth and competence attributions}

Both warmth $(\mathrm{M}=1.69, \mathrm{SD}=1.60, \alpha=$ .86) and competence $(\mathrm{M}=1.02, \mathrm{SD}=1.73$, $\alpha=.87$ ) indices demonstrated good internal reliability. In addition, both indices were above the midpoint of applies "equally to both" parents (i.e., positive traits better described the good parent than the bad parent), $t \mathrm{~s}=12.82,7.11, p \mathrm{~s}<.001$, indicating that our manipulation of parent quality succeeded.

Do warmth and/or competence traits predict custody awards?

An ANCOVA indicated that custody awards were predicted by warmth, $\mathrm{F}(1,141)=4.19, p=.042, \eta_{\mathrm{p}}^{2}=.030$, but not competence, $\mathrm{F}(1,141)=0.04, p=.84$, attributions (after controlling for better parent gender, case, and their interaction). In contrast, warmth attributions were relatedly positively to custody awards, $\mathrm{B}=$ 0.30 [0.01, 0.60], $t=2.05, p=.042$.

Do warmth and/or competence attributions vary according to parents' gender?

Contrary to our prediction, there was no effect of the parent gender manipulation on warmth attributions, $\mathrm{F}(1,143)=0.08, p=$ .78 , after controlling for the effect of case and the interaction. (No effect on competence attributions was observed either, $\mathrm{F}(1,143)=0.02, p=.87$.) Thus, the asymmetry in custody awards did not appear to be mediated by differences in perceived warmth of fathers versus mothers.

In exploratory analyses, we allowed warmth attributions to interact with better parent gender, which revealed a significant effect: $\mathrm{F}(1,140)=4.57, p=.035, \eta_{\mathrm{p}}^{2}=.033$. Thus, rather than mediation, warmth attributions appeared to moderate the asymmetry: i.e., warmth attributions 
predicting custody awards to better mothers, $\mathrm{B}=0.29[0.02,0.55], t=2.14, p=$ .034 , but not better fathers, $\mathrm{B}=0.048[-$ $0.17,0.27$ ], $t=0.42, p=.67$ (see also Table $3)$.

Table 3: Semi-partial correlation between custody awards and three predictors.

\begin{tabular}{lcc} 
& $\begin{array}{c}\text { Better } \\
\text { father }\end{array}$ & $\begin{array}{c}\text { Better } \\
\text { mother }\end{array}$ \\
\hline Warmth traits & $.06(.64)$ & $.26(.02)$ \\
Competence traits & $-.08(.50)$ & $.01(.89)$ \\
$\begin{array}{l}\text { Endorsement of } \\
\text { shared custody }\end{array}$ & $.22(.08)$ & $-.13(.21)$ \\
\hline
\end{tabular}

\section{Discussion}

The observed asymmetry in custody awards did not appear to stem from corresponding mean differences in the attribution of warmth and competence traits to mothers and fathers: Although we replicated the asymmetry in custody awards, no mean differences in the attribution of warmth or competence traits were observed. Thus, we did not replicate the previously-reported association between warmth and women (Eagly, Mladinic, \& Otto, 1991; Rudman \& Kilianski, 2000)-a point we return to in Study 3.

At the same time, warmth traits did appear to predict custody -selectively towards better mothers. In plain terms, the more a good mother was perceived as warm, the more likely she was to obtain sole custody-whereas this was not true for good fathers.

In Study 3, we investigate whether implicit stereotypes about gender and warmth predict custody awards, using the so-called Implicit Attitudes Test (IAT; Greenwald, McGhee, \& Schwartz, 1998), a timed sorting task which computes the average speed at which individuals associate pairs of concepts.

\section{Study 3}

Ample research shows that people implicitly hold stereotypical attitudes that they either do not endorse or do not consciously recognize (Banaji \& Hardin, 1996; Inbar, Pizarro, Knobe, \& Bloom, 2009). In recent years, debate has raged over whether these implicit attitudes influence behavior in a manner independent of explicit goals and intentions (Banaji \& Greenwald, 2013; see also Greenwald et al., 1998; Nosek et al., 2009) or not (Oswald et al., 2015).

The IAT has proven a useful tool in the study of gender stereotypes as well: An influential study asked participants to complete an IAT pairing scientific terms (e.g., 'equation', 'physics', 'NASA') and artistic terms (e.g., 'symphony', 'sculpture', 'drama') to either male or female nouns. The researchers found that science was more strongly associated to male nouns, while the arts were more strongly associated to female nouns (Nosek, Banaji, \& Greenwald, 2002). A subsequent study showed that country-level differences in the strength of the male-science association correlated with differences in male versus female performance on standardized math and science tests (Nosek et al., 2009).

Implicit stereotyping may offer insight into our present pattern of results: Study 1 showed that good fathers were largely awarded shared custody, while good mothers were sometimes awarded primary custody. This asymmetry did not appear to result from explicit attributions of greater warmth-related traits to mothers in Study 2 - since no mean difference in warmth attributions was observed by parent gender. Instead, we observed a selective association between warmth attributions and custody in the Better Mother condition: When mothers deserved custody, the perception of warmth predicted custody awards - in a manner that did not hold for fathers who deserved custody. 
One reason that attributions of warmth to parents may not differ is that baseline expectations vary by gender: If women are expected to display warmth traits more so than men, participants recalibrated the "character and personality" scale in conjunction with our better parent manipulation. We reasoned that this recalibration would not occur on a reaction time task. So in Study 3, we investigate participants' implicit associations between warmth-related traits and female terms.

In order to conceptually replicate the correlation between warmth attributions and custody awards to better mothers observed in Study 2, participants also completed a battery of better-mother cases. ${ }^{2}$ Thus, the purpose of Study 3 was twofold: (1) to investigate whether - through an implicit measure-we observe the genderwarmth association that explicit measures in Study 2 did not reveal, and (2) to conceptually replicate the selective role of warmth-related attributions on custody awards to better mothers.

\section{Methods}

\section{Power analysis}

In Study 2, we observed a small-tomedium effect of warmth on custody awards, $f=.185$, or $\eta_{\mathrm{p}}^{2}=.033$. We conducted a power analysis for withinsubjects ANOVA for our design in Study 3, with 3 repeated-measures and an expected correlation $(r)$ of .40 between measures. Based on this estimate of the effect of warmth on custody awards, we required a sample size of 58 participants to attain recommended statistical power $(1-\beta=.80)$ at $\alpha=.05$.

\section{Participants}

Fifty-six undergraduate law students (37 female, age $_{\text {mean }}=21.8$ years) at the Pontifical Catholic University of Rio de Janeiro were invited to participate in a lab

\footnotetext{
${ }^{2}$ Better-father cases were not used because they were found to be uncorrelated with warmth attributions in Study 2 .
}

study in exchange for course credit. Thus, we fell short of our target sample size, obtaining estimated power of .78 .

\section{Procedure}

Study 3 employed a set of three hypothetical custody disputes, presented in a random order (see Supplementary Materials). The cases described mothers who were either warmer (i.e., less selfish) or more competent (i.e., more disciplined, more successful at work) overall than fathers. For instance, in one case, the mother a non-profit worker and the father a chamber orchestra musician were battling child custody, after the father had lost his job and started drinking (see Supplementary Materials). Participants were asked to award custody on a seven-point scale as in Studies 1 and 2.

In the second part of the experiment, participants completed a Gender-Warmth IAT using Inquisit by Millisecond Software. Participants associated gender categories (Male: "man", "boy", "husband", vs. Female: "woman", "girl", "wife") to warmth characteristics (Warm: "kind", "trustworthy", "patient", vs. Cold: "hostile", "selfish", "insensitive"). Based on past research (Rudman \& Killianksi, 2000), we hypothesized that participants would associate Warm adjectives to Female nouns faster than to Male nouns. The order of presentation of the blocks was counterbalanced (and coded as a dichotomous variable), so half of the participants viewed the hypothesisinconsistent block first while the other half viewed the hypothesis-consistent block first.

In Study 3, we predicted that (1) we would observe an association between warmth and female nouns, and that (2) the strength of gender-warmth associations would correlate with custody awards to mothers.

Concerns about demand characteristics of Study 3 led us to a fixed order for the experiment. Since the IAT is relatively less 
susceptible to desirable responding than the set of custody decisions, custody cases always preceded the IAT. Taking part in the IAT could lead participants to an apprehensive role, compensating for their perceived bias on the custody allocation task. By contrast, custody allocations would likely exert a smaller effect, if any, on IAT behavior. We conducted a small pre-test ( $n$ $=13$ ) which revealed that mothers in our custody cases exhibited average warmth but greater than average competence (see manipulation check in Appendix), so it is unlikely that our custody cases would inflate an association between gender and warmth (see also Rudman \& Glick, 1999).

\section{Results}

In one sample $t$-tests, we observed greater custody allocations to mothers on all three cases, i.e., a significant difference from shared custody $\left(\mathrm{M}_{1}=.71, \mathrm{SD}_{1}=1.07\right.$; $\mathrm{M}_{2}=1.41, \mathrm{SD}_{2}=1.11 ; \mathrm{M}_{3}=.68, \mathrm{SD}_{3}=$ 1.03; all $p \mathrm{~s}<.001)$. In order to evaluate the relationship between implicit attitudes about gender and warmth, we averaged all three custody allocations generating a subject-level mean custody judgment.

\section{Gender-Warmth IAT.}

First, we examined the distribution of reaction times to stereotype-consistent and stereotype-inconsistent blocks. We eliminated one outlier whose average response time to stereotype-inconsistent pairings was over three standard deviations above the group mean. Mean untreated response times for our sample were $900 \mathrm{~ms}$ for the stereotype-consistent block versus $1124 \mathrm{~ms}$ for the stereotype-inconsistent blocks.

$D$-scores were calculated using the improved scoring algorithm in Greenwald, Nosek, and Banaji (2003). Block order had no effect on D-scores, $p>15$. Mean $D$ score $(\mathrm{M}=.44, \mathrm{SD}=.49)$ revealed a moderate Female-Warm association, $t(55)$ $=6.72, p<.0001$.

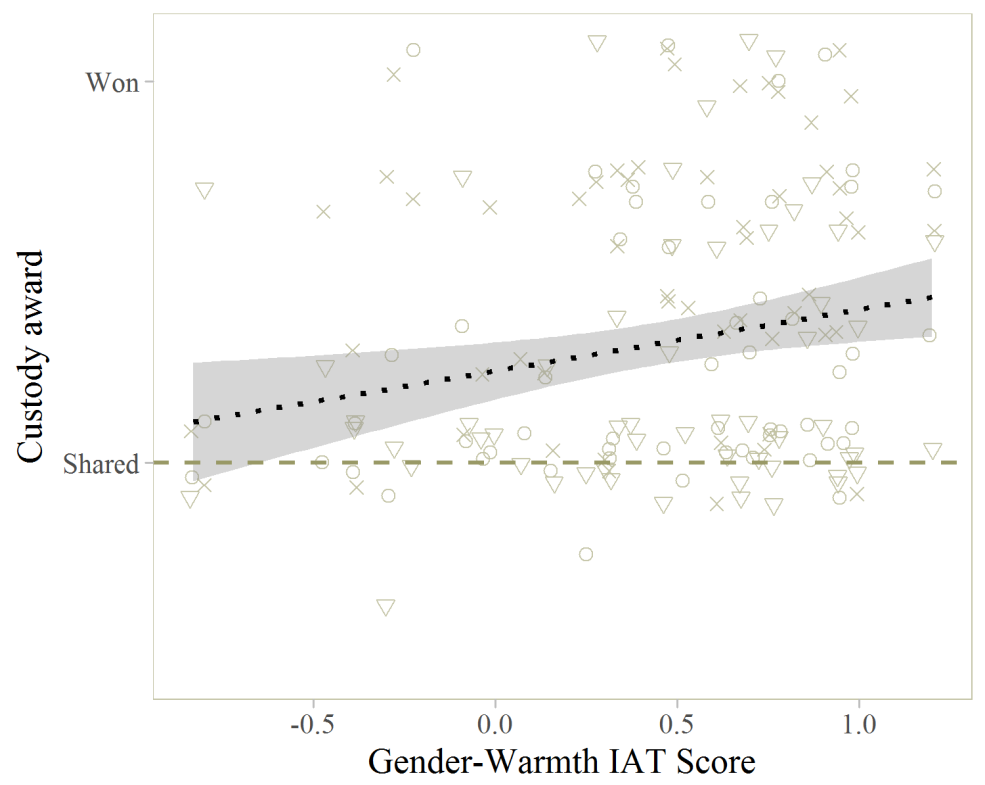

Figure 2. Custody awards by case (shape) and IAT score.

Do implicit stereotypes about gender predict custody allocations?

A mixed-effects model with case and participant as crossed random effects was conducted to assess the influence of Dscores on custody decisions, with random intercepts for each subject and case, and allowing a random slope of D-score by case. The fixed effect of D-score was significant, $\mathrm{B}=0.48[0.12,0.85], z=2.62, p=.009$. A closer look at correlations separately by case revealed that only one relationship was 
statistically significant (Spearman's $\rho \mathrm{s}=$ $.228, .278, .155, p s=.091 .038, .253)$, but remaining correlations trended in the predicted direction. Finally, D-scores predicted mean custody allocations across the three cases, Spearman's $\rho(56)=.355, p=$ .007 (see Figure 2).

\section{Discussion}

Study 3 documented a moderate implicit association between warmth and gender, in line with past research (see also Rudman \& Killianksi, 2000). Namely, female terms (mother, lady, girl) were more easily associated to warmth-related attributes (gentle, kind, trustworthy), while male terms (father, boy, guy) were associated to low warmth (cruel, rude, hostile). Furthermore, the strength of the femalewarm association predicted the proportion of mother-primary custody across three cases of divorce and custody dispute.

Two limitations of Study 3 are worth noting: First, our study was restricted to cases in which greater custody allocations to mothers could be independently justified. Thus, whether the relationship between implicit gender stereotypes and custody decisions holds in other circumstances is not addressed directly by this experimentalthough given the evidence in Study 2, we expect no relationship.

Second, in order to avoid socially desirable responding on our custody cases, the Gender-Warmth IAT was completed after the custody cases. Whether implicit attitudes are influenced by short in-lab tasks is uncertain, with some studies finding modest reductions in the strength of preexisting associations (Blair, Ma \& Lenton, 2001; Dasgupta \& Greenwald, 2001; Dasgupta \& Asgari, 2004) while others show no effect (Gawronski \& Strack, 2004; Gregg, Seibt, \& Banaji, 2006; Petty, Tormala, Briñol, \& Jarvis, 2006). Thus, we acknowledge the possibility that exposure to our divorce cases influenced subsequent responding on the IAT.

\section{General Discussion}

In three studies, we observe evidence of a preference for maternal-primary custody, linked to stereotypes about gender. In Study 1 , an asymmetry in custody awards was observed in three different cultures and languages across matched pairs of custody disputes, such that good mothers received greater custody allocations than did good fathers. In Study 2, we found that warmth attributions did not mediate custody awards. Instead they appeared to moderate awards such that warmth attributions predicted custody awards to good mother, but not good fathers. In Study 3, we observed a general association of female nouns to warmth-related traits, which predicted custody awards as well. Together these results suggest that the asymmetry in custody awards discussed in the literature on child custody depends in part on stereotypes about gender and warmth which are observed through both explicit (Study 2) and implicit (Study 3) methods, and emerges across cultures and languages (Study 1).

Past work on the folk psychology of custody decisions emphasizes the widespread endorsement of shared custody (Braver et al., 2011), which may seem inconsistent with our attention on maternal preference. However, a closer look at Braver and colleagues' results reveals a maternal preference in their data as well: For instance, in one of their studies, "of those who did not select the 'equal living' alternative, far more (28\%) favored maternal primary custody than paternal $(3 \%)$, a huge and significant difference, $t(35)$ $=-3.0, p=.01 "$ " (2011, p. 227). Likewise, our results support Braver et al.'s central conclusion: In all three studies, shared custody was the most popular decision. So, though at first glance our findings may 
seem at odds, our results are remarkably consistent.

From the perspective of ambivalent sexism (Glick \& Fiske, 1996), the present phenomenon might be construed as an obstacle toward gender equality. Positive stereotypes about women have been shown to reduce women's professional aspirations (Montañés et al., 2012; Peach \& Glick, 2013; Rudman \& Heppen, 2003) and support for women's rights (Becker \& Wright, 2011). The maternal preference documented in this study may further aggravate gender imbalance in the workplace, by reinforcing and incentivizing women's involvement in child-rearing roles.

Although our samples consisted of law students and lay respondents, we have some empirical basis to suspect that judges are not entirely insulated from these phenomena. Few studies have directly evaluated whether judges' thinking is equally susceptible to bias and heuristic reasoning (Guthrie, Rachlinski, \& Wistrich, 2001; Rachlinski, Johnson, Wistrich \& Guthrie, 2009; Kneer \& BourgeoisGironde, 2017). One experiment examined the use of typical heuristics in judicial decisions using a sample of magistrate judges: Judges behaved much like laypeople with respect to anchoring, hindsight bias, and egocentric bias, but fared better in response to framing and were less reliant on the representativeness heuristic (Guthrie et al., 2001). Another study looked for implicit racial prejudice in a sample of 133 United States judges (Rachlinski et al., 2009). The study found that White judges particularly harbored a racial bias against Black Americans comparable to that of nonjudges. Moreover, judges' implicit biases somewhat influenced their assessment of juvenile defendants, when the defendant's race was subliminally manipulated. Although the evidence for cognitive bias among professional judges is thus far limited, the above studies alert us of the distinct possibility that stereotypical attitudes shape outcomes in the courtroom as well.

Importantly, we also found an effect of participants' endorsement of shared custody. Belief in shared custody tended to reduce the gender difference in custody awards - primarily, by discouraging sole custody awards in the better-mother condition.

The present findings should not be construed as a defense of shared custody or as evidence in its favor. Separate and more extensive analyses of child outcomes, parental satisfaction, and parent-child relationships evaluate whether shared custody is altogether desirable (Amato, 1993; Bauserman, 2002). Rather, our main contributions are psychological: First, we highlight the dissociation between implicit preferences and explicit endorsement of gender equality and shared custody laws. Second, we document the role of gender stereotypes in judicial contexts, extending and linking two influential research programs on implicit attitudes and ambivalent sexism.

Together with past studies illustrating the effects of judge's ideology (Epstein, Parker \& Segal, 2012; Miles \& Sunstein, 2008) and personal experience (Glynn \& Sen, 2015) on their professional decisions, our current findings cast doubt on strictly formalist models of judicial reasoning and call for a detailed grasp of the psychology behind the interpretation and application of legal norms.

\section{Author Contributions}

ABDE and LLFC and developed the study concept. ABDE, LLFC, NS and IRH were responsible for study design. Data collection was done by ABDE, LLFC and RK, and IRH performed the data analysis. ABDE, LLFC and IRH drafted the manuscript, and RK and NS provided critical revisions. All authors approved the final version of the manuscript for submission. 


\section{References}

Abele, A. E. (2003). The dynamics of masculine-agentic and feminine-communal traits: findings from a prospective study. Journal of Personality and Social Psychology, 85, 768-77.

Amato, P. R. (1993). Children's adjustment to divorce: Theories, hypotheses, and empirical support. Journal of Marriage and the Family, 55(1), 23-38.

Banaji, M. R., \& Greenwald, A. G. (2013). Blindspot: Hidden biases of good people. Delacorte.

Banaji, M. R., \& Hardin, C. D. (1996). Automatic stereotyping. Psychological Science, 7(3), 136-41.

Bauserman, R. (2002). Child adjustment in joint-custody versus sole-custody arrangements: A meta-analytic review. Journal of Family Psychology, 16(1), 91-102.

Blair, I. V., Ma, J. E., \& Lenton, A. P. (2001). Imagining stereotypes away: the moderation of implicit stereotypes through mental imagery. Journal of Personality and Social Psychology, 81(5), 828-841.

Braver, S. L., Ellman, I. M., Votruba, A. M., \& Fabricius, W. V. (2011). Lay judgments about child custody after divorce. Psychology, Public Policy \& Law, 17(2), 212-40.

Becker, J. C., Wright, S. C. (2011). Yet another dark side of chivalry: Benevolent sexism undermines and hostile sexism motivates collective action for social change. Journal of Personality and Social Psychology, 101, 62-77.

Borenstein, M., Hedges, L.V., Higgins, J. P. T., \& Rothstein, H. R. (2009). Introduction to meta-analysis.

Cancian, M., \& Meyer, D.R. (1998). Who gets custody? Demography, 35(2), 147-57.

Christopher, A. N., \& Mull, M. S. (2006). Conservative ideology and ambivalent sexism. Psychology of Women Quarterly, 30(2), 223-30.

Christov-Moore, L., Simpson, E. A., Coudé, G., Grigaityte, K., Iacoboni, M., \& Ferrari, P. F. (2014). Empathy: Gender effects in brain and behavior. Neuroscience \& Biobehavioral Reviews, 46, 604-627.

Dardenne, B., Dumont, M., \& Bollier, T. (2007). Insidious dangers of benevolent sexism: consequences for women's performance. Journal of Personality and Social Psychology, 93(5), 764.

Dasgupta, N., \& Asgari, S. (2004). Seeing is believing: Exposure to counterstereotypic women leaders and its effect on the malleability of automatic gender stereotyping. Journal of Experimental Social Psychology, 40(5), 642-658.

Dasgupta, N., \& Greenwald, A.G. (2001). On the malleability of automatic attitudes: combating automatic prejudice with images of admired and disliked individuals. Journal of Personality and Social Psychology, 81(5), 80014.

Dovidio, J. F., \& Gaertner, S. L. (2000). Aversive racism and selection decisions: 1989 and 1999. Psychological Science, 11(4), 315-319.

Eagly, A. H., Mladinic, A., \& Otto, S. (1991). Are women evaluated more favorably than men? An analysis of attitudes, beliefs, and emotions. Psychology of Women Quarterly, 15(2), 203-16.

Epstein, L., Parker, C. M., \& Segal, J. (2013). Do justices defend the speech they hate? Ingroup bias, opportunism, and the First Amendment. In APSA 2013 Annual Meeting Paper.

Fabricius, W. V., Braver, S. L., Schenck, C., \& Diaz, P. (2010). Custody and parenting time: Links to family relationships and well-being after divorce. In M. E. Lamb (ed.) Role of the father in child development (5th ed.). New York: John Wiley.

Fiske, S. T., Cuddy, A. J. C., \& Glick, P. (2007). Universal dimensions of social cognition: warmth and competence. Trends in Cognitive Sciences, 11(2), 77-83.

Fiske, S. T., Cuddy, A. J. C., Glick, P., \& Xu, J. (2002). A model of (often mixed) stereotype content: competence and warmth respectively follow from perceived status and competition. Journal of Personality and Social Psychology, 82 (6), 878-902.

Flore, P. C., \& Wicherts, J. M. (2015). Does stereotype threat influence performance of girls in stereotyped domains? A metaanalysis. Journal of school psychology, 53(1), 2544.

Furnham, A., Reeves, E., \& Budhani, S. (2002). Parents think their sons are brighter than their daughters: Sex differences in parental 
self-estimations and estimations of their children's multiple intelligences. Journal of Genetic Psychology, 163(1), 24-39.

Gawronski, B., \& Strack, F. (2004). On the propositional nature of cognitive consistency: Dissonance changes explicit, but not implicit attitudes. Journal of Experimental Social Psychology, 40(4), 535-542.

Glick, P., \& Fiske, S. T. (1996). The Ambivalent Sexism Inventory: Differentiating hostile and benevolent sexism. Journal of Personality \& Social Psychology, 70(3), 491-512.

Glick, P., \& Fiske, S. T. (1997). Hostile and benevolent sexism: Measuring ambivalent sexist attitudes toward women. Psychology of Women Quarterly, 21(1), 119-35.

Glick, P., Fiske, S. T., Mladinic, A., Saiz, J., Abrams, D., Masser, B., et al. (2000). Beyond prejudice as simple antipathy: Hostile and benevolent sexism across cultures. Journal of Personality and Social Psychology, 79, 763-775.

Glynn, A. N., \& Sen, M. (2015). Identifying Judicial Empathy: Does Having Daughters Cause Judges to Rule for Women's Issues?. American Journal of Political Science, 59(1), 37-54.

Greenwald, A. G., McGhee, D. E., \& Schwartz, J. K. L. (1998). Measuring individual differences in implicit cognition: The Implicit Association Test. Journal of Personality and Social Psychology, 74, 1464-80.

Greenwald, A. G., Nosek, B. A., \& Banaji, M. R. (2003). Understanding and using the Implicit Association Test: An improved scoring algorithm. Journal of Personality and Social Psychology, 85, 197-216.

Gregg, A. P., Seibt, B., \& Banaji, M. R. (2006). Easier done than undone: Asymmetry in the malleability of implicit preferences. Journal of Personality and Social Psychology, 90 (1), 1-20.

Guthrie, C., Rachlinski, J. J., \& Wistrich, A. J. (2001). Inside the judicial mind. Cornell Law Review, 86(4), 777-830.

Hedges, L., \& Olkin, I. (1985). Statistical models for meta-analysis. New York: Academic Press. Hedges, LV, \& Pigott, TD (2001). The power of statistical tests in meta-analysis. Psychological Methods, 6, 203-217.

Inbar, Y., Pizarro D. A., Knobe, J., \& Bloom, P. (2009). Disgust sensitivity predicts intuitive disapproval of gays. Emotion, 9(3), 435-9.

Instituto Brasileiro de Geografia e Estatística (IBGE; Brazilian Institute of Geography and Statistics). (2014). 2013 Civil Registry Statistics. Available at: http://www.ibge.gov.br/home/estatistica/p opulacao/registrocivil/2013/default xls.sht $\underline{\mathrm{m}}$.

Jost, J. T., \& Kay, A. C. (2005). Exposure to benevolent sexism and complementary gender stereotypes: consequences for specific and diffuse forms of system justification. Journal of personality and social psychology, 88(3), 498.

Jussim, L., Eccles, J., \& Madon, S. (1996). Social perception, social stereotypes, and teacher expectations: Accuracy and the quest for the powerful self-fulfilling prophecy. In Advances in experimental social psychology (Vol. 28, pp. 281-388). Academic Press.

Jussim, L. (2012). Social perception and social reality: Why accuracy dominates bias and selffulfilling prophecy. OUP USA.

Lee, T. L., Fiske, S. T., Glick, P., \& Chen, Z. (2010). Ambivalent sexism in close relationships:(Hostile) power and (benevolent) romance shape relationship ideals. Sex Roles, 62(7-8), 583-601.

Montañés, P., De Lemus, S., \& Bohner, G., Megías, J. L., Moya, M., \& GarciaRetamero, R. (2012). Intergenerational transmission of benevolent sexism from mothers to daughters and its relation to daughters' academic performance goals. Sex Roles, 66, 468-478.

Moss-Racusin, C. A., Dovidio, J. F., Brescoll, V. L., Graham, M. J., \& Handelsman, J. (2012). Science faculty's subtle gender biases favor male students. Proceedings of the National Academy of Sciences, 109(41), 164749.

Nosek, B. A., \& Banaji, M. R. (2001). The go/no-go association task. Social Cognition, 19(6), 625-64.

Nosek, B. A., Banaji, M. R., \& Greenwald, A. G. (2002). Math $=$ male, me = female, therefore math $\neq$ me. Journal of Personality and Social Psychology, 83(1), 44-59.

Nosek, B. A., Smyth, F. L., Sriram, N., Lindner, N. M., Devos, T., Ayala, A., BarAnan, Y., Bergh, R., Cai, H., Gonsalkorale, 
K., Kesebir, S., Maliszewski, N., Neto, F., Olli, E., Park, J., Schnabel, K., Shiomura, K., Tulbure, B., Wiers, R. W., Somogyi, M., Akrami, N., Ekehammar, B., Vianello, M., Banaji, M. R., \& Greenwald, A. G. (2009). National differences in gender-science stereotypes predict national sex differences in science and math achievement. Proceedings of the National Academy of Sciences, 106, 10593-7.

Oswald, F. L., Mitchell, G., Blanton, H., Jaccard, J., \& Tetlock, P. E. (2015). Using the IAT to predict ethnic and racial discrimination: Small effect sizes of unknown societal significance.

Parkinson, P. (2015). Family laws and access to justice. Sydney Law School Research Paper No. 15/52. Available at SSRN: http://ssrn.com/abstract=2620057.

Petty, R.E., Tormala, Z.L., Briñol, P., \& Jarvis, W.B. (2006). Implicit ambivalence from attitude change: an exploration of the PAST model. Journal of Personality and Social Psychology, 90(1), 21-41.

Rachlinski, J. J., Johnson, S. L., \& Wistrich, A. J., \& Guthrie, C. (2009). Does unconscious racial bias affect trial judges? Notre Dame Law Review, 84(3), 1195-1246.

Richell, R. A., Mitchell, D. G. V., Newman, C., Leonard, A., Baron-Cohen, S., \& Blair, R. J. R. (2003). Theory of mind and psychopathy: can psychopathic individuals read the 'language of the eyes'? Neuropsychologia, 41(5), 523-526.

Rudman, L.A., Glick, P. (1999). Feminized management and backlash toward agentic women: the hidden costs to women of a kinder, gentler image of middle managers. Journal of Personality \& Social Psychology, 77(5), 1004-1010.

Rudman, L. A., \& Heppen, J. B. (2003). Implicit romantic fantasies and women's interest in personal power: A glass slipper effect? Personality and Social Psychology Bulletin, 29, 1357-1370.

Rudman, L. A., \& Killianski, S. E. (2000). Implicit and explicit attitudes toward female authority. Personality and Social Psychology Bulletin, 26(11), 1315-28.

Stamps, L. E. (2002). Maternal preference in child custody decisions. Journal of Divorce \& Remarriage, 37(1-2), 1-11.

Stricker, L. J., \& Ward, W. C. (2004). Stereotype Threat, Inquiring About Test Takers' Ethnicity and Gender, and Standardized Test Performance 1. Journal of Applied Social Psychology, 34(4), 665-693.

Tjaden, P. G., \& Thoennes, N. (2000). Extent, nature, and consequences of intimate partner violence: Findings from the National Violence Against Women Survey (Vol. 181867). Washington, DC: National Institute of Justice.

van Etten, M. L. V., Neumark, Y. D., \& Anthony, J. C. (1999). Male-female differences in the earliest stages of drug involvement. Addiction, 94(9), 1413-1419.

Viechtbauer, W. (2010). Conducting metaanalyses in $\mathrm{R}$ with the metafor package. Journal of Statistical Software, 36(3), 1-48.

Warshak, R. A. (1996). Gender bias in child custody decisions. Family Court Review, 34, 396-409. 